\title{
Correction: Investigating rare pathogenic/likely pathogenic exonic variation in bipolar disorder
}

\author{
Xiaoming Jia - Fernando S. Goes (1) - Adam E. Locke $(\mathbb{D}) \cdot$ Duncan Palmer (i) $\cdot$ Weiqing Wang $(\mathbb{D} \cdot$ \\ Sarah Cohen-Woods - Giulio Genovese $(\mathrm{D})$ Anne U. Jackson (D) Chen Jiang - Mark Kvale - Niamh Mullins • \\ Hoang Nguyen (D) - Mehdi Pirooznia (D) Margarita Rivera • Douglas M. Ruderfer • Ling Shen • Khanh Thai • \\ Matthew Zawistowski - Yongwen Zhuang • Gonçalo Abecasis (D) Huda Akil • Sarah Bergen (D) \\ Margit Burmeister (D) Sinéad Chapman - Melissa DelaBastide • Anders Juréus • Hyun Min Kang • Pui-Yan Kwok $(D)$ \\ Jun Z. Li (D) - Shawn E. Levy (D) - Eric T. Monson • Jennifer Moran • Janet Sobell • Stanley Watson (ID) \\ Virginia Willour • Sebastian Zöllner • Rolf Adolfsson • Douglas Blackwood (D) Michael Boehnke (D) \\ Gerome Breen (D) - Aiden Corvin • Nick Craddock • Arianna DiFlorio • Christina M. Hultman • Mikael Landen (ID • \\ Cathryn Lewis $(\mathbb{D} \cdot$ Steven A. McCarroll $(\mathbb{D} \cdot$ W. Richard McCombie - Peter McGuffin - Andrew Mclntosh $\mathbb{D}$ - \\ Andrew McQuillin (D) - Derek Morris (D) - Richard M. Myers • Michael O'Donovan (D) Roel Ophoff • Marco Boks (D) \\ Rene Kahn (D) - Willem Ouwehand (D) - Michael Owen (i) - Carlos Pato - Michele Pato - Danielle Posthuma • \\ James B. Potash (D) - Andreas Reif (D) Pamela Sklar • Jordan Smoller • Patrick F. Sullivan • John Vincent (D) \\ James Walters • Benjamin Neale (D) Shaun Purcell (D) Neil Risch • Catherine Schaefer (D) Eli A. Stahl (D) • \\ Peter P. Zandi . Laura J. Scott $(\mathbb{D}$
}

Published online: 5 March 2021

(c) The Author(s) 2021. This article is published with open access

Correction to: Molecular Psychiatry https://doi.org/10.1038/s41380-020-01006-9

Following publication of this article, the authors informed us that one author's name was spelled incorrectly. The correct spelling is Sinéad Chapman.

This has now been corrected in both the PDF and HTML versions of this article.
Open Access This article is licensed under a Creative Commons Attribution 4.0 International License, which permits use, sharing, adaptation, distribution and reproduction in any medium or format, as long as you give appropriate credit to the original author(s) and the source, provide a link to the Creative Commons license, and indicate if changes were made. The images or other third party material in this article are included in the article's Creative Commons license, unless indicated otherwise in a credit line to the material. If material is not included in the article's Creative Commons license and your intended use is not permitted by statutory regulation or exceeds the permitted use, you will need to obtain permission directly from the copyright holder. To view a copy of this license, visit http://creativecommons. org/licenses/by/4.0/. 